\title{
A FALTA DE LAICIDADE E A INTOLERÂNCIA RELIGIOSA DAS ESCOLAS PÚBLICAS BRASILEIRAS E O PAPEL DA DISCIPLINA DE ENSINO RELIGIOSO
}

\author{
THE LACK OF LAITY AND THE RELIGIOUS INTOLERANCE OF THE BRAZILIAN \\ PUBLIC SCHOOLS AND THE ROLE OF THE DISCIPLINE OF RELIGIOUS \\ EDUCATION
}

Michelle de Paula Pupo ${ }^{1}$

RESUMO: Este artigo se propõe a tratar sobre a falta de laicidade das escolas públicas brasileiras e a importância da disciplina de ensino religioso no combate a intolerância religiosa dentro das escolas públicas. O Brasil em sua Constituição é um Estado laico, mas no cotidiano percebemos que é somente uma mera formalidade, um exemplo são os feriados cristãos em nosso calendário, ainda existe intolerância religiosa no Brasil e a escola é um espaço que não foge disso. Buscando analisar através de reportagens que mostram essa falta de laicidade e a intolerância religiosa dentro das escolas públicas brasileiras, tanto por parte de professores como de alunos.

Palavras-chave: laicidade, educação, intolerância.

ABTRACT: This article proposes to deal with the lack of secularity of Brazilian public schools and the importance of the discipline of religious education in combating religious intolerance within public schools. Brazil in its Constitution is a secular state, but in everyday life we realize that it is only a mere formality, an example is the Christian holidays in our calendar, there is still religious intolerance in Brazil and the school is a space that does not escape from it. Seeking to analyze through reports that show this lack of secularism and religious intolerance within Brazilian public schools, both by teachers and students.

Keywords: secularity, education, intolerance.

\section{INTRODUÇÃO}

Atualmente no Brasil existem uma pluralidade muito grande de crenças e religiões e isso se deve ao seu passado histórico no qual em sua colonização sofreu influências da cultura africana que veio para o país para ser escravizada, pela diversidade de culturas indígenas que já existiam no país a influência portuguesa que também fez parte da colonização brasileira e de diversas culturas europeias que vieram posteriormente para o país, cada local do território brasileiro possui a sua diversidade religiosa.

\footnotetext{
${ }^{1}$ Graduação em ciências sociais pela FASF- Faculdade Sagrada Família; especialização em metodologia do ensino religioso e filosofia; especialização em educação especial e especialização em psicopedagogia escolar pela FAPI- Faculdade de Pinhais; mestranda em História, cultura e identidades pela UEPG- Universidade Estadual de Ponta Grossa. E-mail: michellepupo18@gmail.com.
} 
Nada mais do que necessário em um país com uma pluralidade cultural e religiosa respeitar os princípios de cada religião, vemos nas mídias que o Brasil é considerado um país laico, ou seja, não possui uma religião oficializada e possui dentro de sua Constituição artigos que tratam sobre o respeito à diversidade religiosa.

Mas, no entanto, sabemos que essas diversidades não são respeitadas por todos e a escola por ser um ambiente de socialização ela abarca grande parte dessas diversidades e é onde por parte de professores, gestores, diretores e alunos há um grande desrespeito com as demais religiões e certa imposição do Cristianismo em grande parte dos casos.

No decorrer do trabalho mostram-se os princípios da Constituição brasileira que tratam desses termos, também será demostrado que a imposição de uma religião sobre a outra vem desde a colonização do Brasil com o ensino jesuítico e possui raízes até hoje em nossa cultura, e para pensarmos atualmente se ainda existe essa falta de laicidade dentro das escolas públicas brasileiras faz-se uso de reportagens que tratam sobre o assunto, nos fazendo refletir sobre a importância da disciplina de ensino religioso quando ministrada corretamente pode fazer toda a diferença para aprendermos que possuímos diversas crenças, cada um sabe no que acreditar, e para um bom convívio o essencial é o respeito.

\section{A FALTA DE LAICIDADE E A INTOLERÂNCIA RELIGIOSA DAS ESCOLAS PÚBLICAS BRASILEIRAS E O PAPEL DA DISCIPLINA DE ENSINO RELIGIOSO}

O Brasil tem uma formação cultural muito rica, com contribuição de diversas culturas na sua formação, como a cultura africana, a indígena e a europeia, possuindo então uma formação multicultural. Ouvimos através das mídias, reivindicações de movimentos sociais que o Brasil, é considerado um país laico, que seria não ter oficializada uma religião no país. Um Estado laico significa defender a liberdade religiosa dos cidadãos do seu país, visto que o Brasil é um país multicultural e sendo multicultural possui diversas religiões diversas formas de pensar e nada mais do que justo e necessário ser um país laico, pelo menos ele o é na formalidade.

Segundo Rassar (2012), o Brasil passou a ser um Estado laico logo após da Proclamação da República em 1889 e a partir do Decreto n 119 -A de 07/01/1890 de autoria de Ruy Barbosa, antes desse decreto possuía-se apenas com a Constituição de 1824 apenas a liberdade de crença, mas não a liberdade de culto, o Brasil possuía a religião católica como oficial e era permitido apenas as demais religiões o culto no ambiente doméstico. Vejamos o decreto 119-A de 7 de janeiro de 1890: 


\section{Decreto 119-A, de 7 de janeiro de 1890}

Art. $1^{\circ} \mathrm{E}^{\prime}$ prohibido á autoridade federal, assim como á dos Estados federados, expedir leis, regulamentos, ou actos administrativos, estabelecendo alguma religião, ou vedando-a, e crear differenças entre os habitantes do paiz, ou nos serviços sustentados á custa do orçamento, por motivo de crenças, ou opiniões philosophicas ou religiosas.

Art. $2^{\circ}$ a todas as confissões religiosas pertence por igual a faculdade de exercerem o seu culto, regerem-se segundo a sua fé e não serem contrariadas nos actos particulares ou publicos, que interessem o exercicio deste decreto.

Art. $3^{\circ}$ A liberdade aqui instituida abrange não só os individuos nos actos individuaes, sinão tabem as igrejas, associações e institutos em que se acharem agremiados; cabendo a todos o pleno direito de se constituirem e viverem collectivamente, segundo o seu credo e a sua disciplina, sem intervenção do poder publico.

Art. $4^{\circ}$ Fica extincto o padroado com todas as suas instituições, recursos e prerogativas.

Art. $5^{\circ} \mathrm{A}$ todas as igrejas e confissões religiosas se reconhece a personalidade juridica, para adquirirem bens e os administrarem, sob os limites postos pelas leis concernentes á propriedade de mão-morta, mantendo-se a cada uma o dominio de seus haveres actuaes, bem como dos seus edificios de culto.

Art. $6^{\circ} \mathrm{O}$ Governo Federal continúa a prover á congrua, sustentação dos actuaes serventuarios do culto catholico e subvencionará por anno as cadeiras dos seminarios; ficando livre a cada Estado o arbitrio de manter os futuros ministros desse ou de outro culto, sem contravenção do disposto nos artigos antecedentes.

Art. $7^{\circ}$ Revogam-se as disposições em contrario.

Sala das sessões do Governo Provisorio, 7 de janeiro de $1890,2^{\circ}$ da Republica.(DECRETO 119-A, 07/01/1890)

\section{Somente com esse decreto de Ruy Barbosa em 1890, houve a separação entre Estado}

e Igreja, e o Brasil deixou de ter uma religião oficial. Vejamos agora o que a Constituição atual brasileira decretada em 1988, no que se refere a esses termos:

\section{Constituição Federal de 1988}

Nós, representantes do povo brasileiro, reunidos em Assembléia Nacional Constituinte para instituir um Estado Democrático, destinado a assegurar o exercício dos direitos sociais e individuais, a liberdade, a segurança, o bem-estar, o desenvolvimento, a igualdade e a justiça como valores supremos de uma sociedade fraterna, pluralista e sem preconceitos, fundada na harmonia social e comprometida, na ordem interna e internacional, com a solução pacífica das controvérsias, promulgamos, sob a proteção de Deus, a seguinte CONSTITUIÇÃO DA REPÚBLICA FEDERATIVA DO BRASIL.

Art. $5^{\circ}$ Todos são iguais perante a lei, sem distinção de qualquer natureza, garantindo-se aos brasileiros e aos estrangeiros residentes no País a inviolabilidade do direito à vida, à liberdade, à igualdade, à segurança e à propriedade, nos termos seguintes:

VI - é inviolável a liberdade de consciência e de crença, sendo assegurado o livre exercício dos cultos religiosos e garantida, na forma da lei, a proteção aos locais de culto e a suas liturgias; $[\ldots]$

Art. 19. É vedado à União, aos Estados, ao Distrito Federal e aos Municípios: I - estabelecer cultos religiosos ou igrejas, subvencioná-los, embaraçar-lhes o funcionamento ou manter com eles ou seus representantes relações de dependência ou aliança, ressalvada, na forma da lei, a colaboração de interesse público;

II - recusar fé aos documentos públicos;

\footnotetext{
${ }^{2}$ http://www.planalto.gov.br/ccivil 03/decreto/1851-1899/d119-a.htm> . Acesso em: 30 set. 2015.
} 
III - criar distinções entre brasileiros ou preferências entre si.[..] (CONSTITUIÇÃO FEDERAL DE 1988, 05/10/1988) ${ }^{3}$

Segundo Zylbersztajn (2012), a laicidade brasileira não é expressa na Constituição, mas que este princípio está garantido pela interpretação do conjunto constitucional.

Mas até onde o Brasil é considerado um Estado Laico? O artigo n5 inciso VI, nos mostra que temos liberdade de escolha de crença, o livre exercício para a realização de cultos e proteção aos lugares onde são realizados,

O artigo 19 diz que é proibido ao País estabelecer vínculos de cultos religiosos, subvenciona-los, ou seja, prestar auxílio ou subsidiar cultos e manter relacionamentos de aliança.

Mas, nota-se que a Constituição foi promulgada "sob a proteção de Deus" e outros exemplos clássicos que seriam os feriados cristãos no calendário brasileiro, o que seria um desrespeito com as demais religiões por não possuírem nenhuma data decretada como feriado, o que nos mostra como o catolicismo já está impregnado na nossa cultura desde o Brasil colônia com a vinda dos jesuítas para a catequização dos indígenas.

\subsection{OS JESUÍTAS E A CULTURA CRISTÃ}

De acordo com Oliveira (2011), os jesuítas ou a Companhia de Jesus foram responsáveis pela primeira rede de educação no país integrando as culturas indígenas com as europeias. A ordem jesuítica foi fundada por Inácio Laiola em 1534 e em 1540 foi aprovada pelo papa Paulo III. Eles formaram os primeiros grupos de missionários a deixar a Europa e se dedicar a catequese nas novas terras descobertas.

Segundo Incontri e Bigheto (2004), é somente no século XVIII que começam aparecer as propostas de uma escola sem religião com os pensadores iluministas e a Revolução Francesa se encarrega dessa realização, a educação passa da igreja para tarefa do Estado. Antes disso a Igreja católica possuía uma forte influencia na educação. E em 1763 os jesuítas são expulsos da França e nessa época o ensino religioso deveria ser ministrado durante os cultos e o papel da escola era transmitir uma educação moral racional.

De acordo com Sousa (2011), o plano de estudos dos jesuítas era o Ratio Studiorum e foi criado para manter a soberania católica na educação esse documento organizava e regia a

\footnotetext{
${ }^{3}$ http://www.planalto.gov.br/ccivil 03/Constituicao/Constituicao.htm> . Acesso em: 30 set. 2015.
} 
estrutura e o currículo das escolas e os colégios se mantinham fiéis aos seus princípios, foi utilizados em vários países inclusive no Brasil.

Nota-se que desde o período do Brasil colônia com a vinda do ensino jesuítico ao país, a imposição de uma religião sobre a outra, os jesuítas através de um método de muita disciplina e rigidez queriam catequisar e alfabetizar os indígenas, impondo de certa forma a religião cristã como correta, desconsiderando suas crenças e seus valores culturais.

Mas atualmente vemos que nem todos os cidadãos respeitam o que está na Constituição, pois ainda há muita discriminação com as demais religiões e crenças, não há nem ao menos o respeito de que cada um pode escolher no que acreditar.

\subsection{O COTIDIANO NAS ESCOLAS PÚBLICAS BRASILEIRAS}

Sendo o Brasil considerado mesmo que formalmente um Estado laico e voltando a atenção agora para a educação e as escolas públicas brasileiras, estas também deveriam ser laicas e não tentar ensinar nem impor uma determinada religião para seus alunos o que muitas vezes não é o que ocorre, pois, muitas escolas não respeitam algumas utilizam dentro do ambiente escolar e dentro da sala de aula objetos religiosos assim como os próprios professores tentam passam seus valores religiosos como corretos.

Percebe-se então a importância da disciplina de ensino religioso para aprendermos a respeitar as diferentes religiões, crenças e cultos.

Visto que a disciplina de ensino religioso tem por objetivo ensinar o respeito a diversidade cultural religiosa do Brasil, vejamos a LDBE 9394/96 (Lei de Diretrizes e bases da educação), especificamente o artigo 33, que regulamenta o ensino religioso nas escolas públicas brasileiras:

\footnotetext{
Art. 33. O ensino religioso, de matrícula facultativa, é parte integrante da formação básica do cidadão e constitui disciplina dos horários normais das escolas públicas de ensino fundamental, assegurado o respeito à diversidade cultural religiosa do Brasil, vedadas quaisquer formas de proselitismo. (Redação dada pela Lei $n^{\circ} 9.475$, de 22.7.1997)

$\$ 1^{\circ}$ Os sistemas de ensino regulamentarão os procedimentos para a definição dos conteúdos do ensino religioso e estabelecerão as normas para a habilitação e admissão dos professores.

$\S \mathbf{2}^{\mathbf{0}}$ Os sistemas de ensino ouvirão entidade civil, constituída pelas diferentes denominações religiosas, para a definição dos conteúdos do ensino religioso."4
}

\footnotetext{
${ }^{4}$ http://www.planalto.gov.br/CCIVIL 03/leis/L9394.htm> . Acesso em: 30 set. 2015.
} 
Mas isso muitas vezes não ocorre esse respeito a diversidade religiosa em algumas escolas públicas brasileiras, pois segundo, Zylbersztajn (2012), algumas regulamentações estaduais e municipais desrespeitam o caráter social e filosófico da disciplina de ensino religioso tornando as salas de aulas das escolas públicas brasileiras um local de proselitismo de determinadas religiões, ou seja, muitas vezes o próprio professor de ensino religioso ao invés de ensinar as diversidades ele quer ensinar sua religião, visto que dentro de uma sala de aula existem diversos alunos de diversas crenças e religiões. Aqui podemos perceber o quanto é importante uma boa formação e a conscientização do papel do professor na área de ensino religioso.

Mas se voltarmos nossa atenção para a escola pública também notamos a falta de laicidade, pois dentro de salas de aula símbolos religiosos como crucifixos como também muitas escolas antes de começaram a aula realizam a oração cristã do Pai-nosso.

Como exemplo, vejamos a reportagem da Revista Fórum publicada no dia 16/04/2013, reportagem de Paulo Lopes com a seguinte manchete: "Reação de aluno ateu a bulluing acaba com o pai-nosso na escola":

No início deste mês, o estudante Ciel Vieira, 17, de Miraí (MG), não se conformou com a atitude da professora de geografia Lila Jane de Paula de iniciar a aula com um pai-nosso. Então, ele se manteve em silêncio, o que levou a professora a dizer: "Jovem que não tem Deus no coração nunca vai ser nada na vida".

Era um recado para ele. Na classe, todos sabem que ele é ateu. A escola se chama Santo Antônio e é do ensino estadual de Minas. Miraí é uma cidade pequena. Tem cerca de 14 mil habitantes e fica a $300 \mathrm{~km}$ de Belo Horizonte.

Quando houve outra aula, Ciel disse para a professora que ela estava desrespeitando a Constituição que determina a laicidade do Estado. Lila afirmou não existir nenhuma lei que a impeça de rezar, o que ela faz havia 25 anos e que não ia parar, mesmo se ele levasse um juiz à sala de aula.

$\mathrm{Na}$ aula seguinte, Ciel chegou atrasado, quando a oração estava começando, e percebeu ele tinha sido incluído no pai-nosso. Aparentemente com a aquiescência da professora, alguns estudantes substituíram a frase "livrai-nos do mal" por "livrar-nos do Ciel".

O rapaz gravou o bullying com o seu celular e o reproduziu em um vídeo no Youtube, onde expôs a sua indignação.

E só então, por causa da repercussão do vídeo, a direção da escola e a inspetoria passaram a cuidar do caso, mas para dar um jeitinho, de modo que a professora pudesse continuar a rezar o pai-nosso sem a presença de Ciel.

Contudo, a secretaria de Estado da Educação, ao ser procurada pela Folha de S.Paulo, informou que a professora Lila tinha sido orientada a parar de rezar. Não se tem a versão da professora porque ela não quis falar com a imprensa. Lila é católica. $\mathrm{O}$ estudante gravou um segundo vídeo para contar o desfecho do imbróglio e agradecer o apoio da Atea (Associação Brasileira dos Ateus e Agnósticos), de familiares e dos parentes.

Ao jornal, a mãe de Ciel comentou: “Até chorei quando vi o vídeo [o primeiro] dele. Meu filho sempre foi um aluno ético".

Ela é espírita. 
“Livrai-nos do Ciel, amém” (REVISTA FÓRUM, 16/04/2013)

Como vemos na reportagem acima o aluno questiona a professora por rezar o painosso dizendo que ela estava desrespeitando a Constituição, e mesmo assim a professora continuou realizando a oração e ainda expôs o aluno a uma situação constrangedora no momento em que troca a expressão da oração "livrai-nos do mal" por "livrai-nos do Ciel" que é o nome do garoto, insinuando que o menino por ser ateu era considerado um mal, como também foi observado na reportagem que a escola ao invés de tomar uma providência, ela continuou dando seu "jeitinho" para que a professora continuasse a realizar suas orações em sala.

Nessa outra reportagem do site Pragmatismo político do colunista Luiz Soares do dia 13/11/2012, com a Manchete "Estudantes evangélicos se negam a fazer trabalho sobre cultura afro-brasileira", vemos uma perspectiva dos alunos a respeitos:

\begin{abstract}
Estudantes evangélicos se negam a fazer trabalho sobre cultura afro-brasileira Alunos se negaram a fazer projeto sobre cultura afro-brasileira, alegando 'princípios religiosos', afirmando que o trabalho faz apologia ao 'satanismo e ao homossexualismo' $\mathrm{O}$ protesto de um grupo de 13 alunos evangélicos do ensino médio da escola estadual Senador João Bosco Ramos de Lima - na avenida Noel Nutels, Cidade Nova, Zona Norte -, que se recusaram a fazer um trabalho sobre a cultura afro-brasileira - gerou polêmica entre os grupos representativos étnicos culturais do Amazonas.

Os estudantes se negaram a defender o projeto interdisciplinar sobre a 'Preservação da Identidade Étnico-Cultural brasileira' por entenderem que o trabalho faz apologia ao "satanismo e ao homossexualismo", proposta que contraria as crenças deles. Por conta própria e orientados pelos pastores e pais, eles fizeram um projeto sobre as missões evangélicas na África, o que não foi aceito pela escola. Por conta disso, os alunos acamparam na frente da escola, protestando contra o trabalho sobre cultura afro-brasileira, atitude que foi considerada um ato de intolerância étnica e religiosa. "Eles também se recusaram a ler obras como O Guarany, Macunaíma, Casa Grande Senzala, dizendo que os livros falavam sobre homossexualismo", disse o professor Raimundo Cardoso. Para os alunos, a questão deve ser encarada pelo lado religioso. "O que tem de errado no projeto são as outras religiões, principalmente o Candomblé e o Espiritismo, e o homossexualismo, que está nas obras literárias. Nós fizemos um projeto baseado na Bíblia", alegou uma das alunas. (PRAGMATISMO POLÍTICO, 13/11/2012). ${ }^{6}$
\end{abstract}

$\mathrm{Na}$ seguinte reportagem vemos um professor que pede um trabalho sobre a cultura afro-brasileira e vemos alunos evangélicos que se negam a fazer o trabalho por alegarem que o que foi pedido no trabalho vai contra seus "princípios religiosos", essa reportagem é

\footnotetext{
5 Fonte: https://www.revistaforum.com.br/2013/04/16/reacao-de-aluno-ateu-a-bullying-acaba-com-painosso-na-escola/. Acesso em:30/09/2015.

${ }^{6}$ Fonte: http://www.pragmatismopolitico.com.br/2012/11/estudantes-evangelicos-trabalho-cultura-afrobrasileira.html. Acesso: 30/09/2015.
} 
polêmica pelo seguinte motivo, ao mesmo tempo em que os alunos evangélicos querem ser respeitados eles não querem respeitar a religião e a cultura alheia, o que nos leva a pensar a questão da intolerância religiosa e até voltar a uma visão antropológica de etnocentrismo. De acordo com Rocha (1984,p.7), “etnocentrismo é uma visão do mundo onde o nosso próprio grupo é tomado como centro de tudo e todos os outros são pensados e sentidos através dos nossos valores, nossos modelos, nossas definições do que é a existência”, ou seja, segundo a visão etnocentrista vemos a nossa cultura, a nossa crença, a nossa maneira de viver como superior as demais, o que não pertence a nossa cultura é vista como um costume estranho, e não é característica de uma única sociedade. Essa visão etnocentrista foi responsável pela criação de intolerância e preconceito.

Os alunos se mostram contra o trabalho que o professor propôs e fazem um protesto na frente da escola e são visto como intolerantes, mas, no entanto existe a Lei n. 10.639/3, que inclui no currículo oficial das escolas a obrigatoriedade do ensino da história e da cultura afrobrasileira, ou seja, é obrigatório o ensino da cultura afro-brasileira nas escolas já devido a sua marginalização durante anos no Brasil.

Casos de intolerância com religiões de matriz africana são cada vez mais frequentes, vejamos essa outra reportagem do site Extra, de Breno Boechat, onde uma aluna é agredida por sua colega por pertencer a religião do Candomblé:

Estudante agredida por intolerância religiosa dentro de escola não quer voltar ao colégio

Há um mês, a adolescente Agnes, de 14 anos, não quer voltar ao Colégio Estadual Alfredo Parodi por vergonha. No dia 31 de agosto, a jovem foi agredida por uma colega de turma, dentro da escola, por intolerância religiosa. A motivação para a agressão foi uma foto, postada no dia anterior em uma rede social, em que a menina aparece ao lado da mãe e de uma amiga, as três do Candomblé.

- A gente ia levar uma amiga no aeroporto e tirou uma foto com ela lá. A Agnes foi marcada na foto e viram no Facebook dela. No dia seguinte, na primeira aula, uma menina disse que não queria ficar perto da Agnes porque ela era da macumba. A Agnes começou a explicar o que era, mas depois falaram que iam chutá-la, porque ela é da macumba. A menina foi e chutou a Agnes, que caiu com a cabeça na parede — explica a mãe da adolescente, Dega Maria Pascoal.[...](EXTRA, 30/09/2015). ${ }^{7}$

Nessa reportagem vemos um caso muito mais grave de intolerância religiosa, pois ela chega a virar uma agressão, fazendo com que a menina não queira mais voltar a escola por ser vítima de preconceito e discriminação devido a religião que ela pertence.

${ }^{7}$ Fonte: http://extra.globo.com/noticias/brasil/estudante-agredida-por-intolerancia-religiosa-dentro-deescola-nao-quer-voltar-ao-colegio-17650415.html. Acesso: 30/09/2015. 
Todos os dias existem inúmeros casos de agressão, discriminação e preconceito devido a intolerância religiosa, por isso é de extrema importância a disciplina de ensino religioso nas escolas brasileiras, pois como já foi citado acima o Brasil é um país multicultural de possuímos um diversas maneiras de viver, de pensar, diversas crenças convivendo junto e é mais do que necessário aprender a respeitar as diferenças, tendo um país laico e uma escola que seja efetivamente laica ensinando que existem diferentes maneiras de pensar e que só porque ela não corresponde aos seus princípios ela está errada.

Também é muito importante que o professor de ensino religioso tenha a consciência do papel em que a disciplina deve cumprir e não inverter os seus valores, como também é importante para todos os professores de todas as disciplinas, para diretores, pedagogos e todos os funcionários da escola que esta pertence a um país que se diz laico, e esta instituição também o é, então no mínimo dentro dela devem ser respeitadas todas as formas de manifestações religiosas.

\section{CONSIDERAÇÕES FINAIS}

Este trabalho buscou analisar a falta de laicidade e de intolerância religiosa nas escolas públicas brasileiras e através de algumas reportagens foi possível notar que ainda isso está muito presente no cotidiano escolar, tanto por parte de alunos como de professores e gestores da escola.

O Brasil sendo um país multicultural um país onde as pessoas convivem constantemente com uma diversidade de crenças e religiões é fundamental aprender a conviver e respeitar essas diferenças que são inúmeras e a escola tem papel fundamental, pois é um ambiente de socialização e aprendizado constante.

Assim como a disciplina de ensino religioso que se cumprido seu papel corretamente auxilia e muito no respeito à diversidade cultural. Pois ainda no Brasil existem muitas religiões que são marginalizadas como vimos na reportagem acima o caso da menina que pertencia ao Candomblé e sofreu agressões dentro da escola, assim como a Umbanda e o Espiritismo sofrem de muito preconceito.

Devemos cada dia mais aprender a respeitar o outro entender que assim como queremos ser respeitados, o outro merece respeito não pensando apenas na sua escolha religiosa, mas também em todos os âmbitos da sociedade como a escolha da sua sexualidade, a sua cor de pele entre outros. 
De acordo com Incontri e Bigheto (2004), o professor mais indicado para a disciplina de ensino religioso é aquele que sabe respeitar outros credos e não somente o seu e não procura doutrinar os alunos dentro de suas concepções. Devemos transformar a escola em um espaço de livre pensamento e de construção de conhecimento.

\section{REFERÊNCIAS}

BRASIL. Constituição (1890). Decreto no 119-A, de 07 de janeiro de 1890. Prohibe A Intervenção da Autoridade Federal e dos Estados Federados em Materia Religiosa, Consagra A Plena Liberdade de Cultos, Extingue O Padroado e Estabelece Outras Providencias. Sala das sessões do Governo Provisorio, 07 jan. 1890. Disponível em: <http://www.planalto.gov.br/ccivil_03/decreto/1851-1899/d119-a.htm>. Acesso em: 30 set. 2015.

BRASIL. Constituição (1988). Constituição Federal nº Artigo 19, inciso IV, de 05 de outubro de 1988. dos Direitos e Garantias Fundamentais e dos Direitos e Deveres Individuais e Coletivos. Brasília, 05 out. $1988 . \quad$ Disponível em: <http://www.planalto.gov.br/ccivil_03/Constituicao/Constituicao.htm>. Acesso em: 30 set. 2015.

BRASIL. Constituição (1996). Lei de Diretrizes e Bases da Educação no 9.394, de 20 de dezembro de 1996. Inclusão do Ensino Religioso. Brasília, 20 dez. 1996. Disponível em: <http://www.planalto.gov.br/CCIVIL_03/leis/L9394.htm>. Acesso em: 30 set. 2015.

INCONTRI, Dora; BIGHETO, Alessandro Cesar. Ensino confessional, laico ou interreligioso? Qual a melhor resposta? 2004. Disponível em: <http://gper.com.br/documentos/ensino_confessional.pdf>. Acesso em: 03 out. 2015.

OLIVEIRA, Amanda Melissa Bariano de. AÇÃO EDUCACIONAL JESUÍTICA NO BRASIL COLONIAL. Revista Brasileira de História das Religiões, Maringá, v. 9, n. 3, p.18, jan. 2011. Disponível em: <http://www.dhi.uem.br/gtreligiao/pdf8/ST6/005 - AMANDA MELISSA BARIANO DE OLIVEIRA.pdf>. Acesso em: 30 set. 2015.

RASSAR, Andrea. Brasil: A Laicidade e a Liberdade Religiosa desde a Constituição da República Federativa de 1988.2012. Disponível em: <http://www.egov.ufsc.br/portal/conteudo/brasil-laicidade-e-liberdade-religiosa-desdeconstituição-da-república-federativa-de-1988>. Acesso em: 30 set. 2015.

ROCHA, Everardo. O que é etnocentrismo? São Paulo: Brasiliense, 1984. Disponível em: <http://sites.usjt.br/leonarde/oqueeetnocentrismo.pdf>. Acesso em: 30 set. 2015.

SOUSA, Manuela Pereira de. UM BREVE HISTÓRICO DO PERÍODO JESUÍTICO NO BRASIL E O RATIO STUDIORUM. 2011. Disponível em: <http://www.uninove.br/PDFs/Mestrados/Educação/Manuela Pereira de Sousa.pdf>. Acesso em: 03 out. 2015. 
ZYLBERSZTAJN, Joana. O princípio da laicidade na Constituição Federal de 1988. 2012. 248 f. Tese (Doutorado) - Curso de Direito, Faculdade de Direito da Universidade de São Paulo, São Paulo, 2012. Disponível em: <file:///C:/Users/Michelle/Downloads/Joana_Zylbersztajn_TESE_Corrigido (1).pdf>. Acesso em: 03 out. 2015.

http://www.planalto.gov.br/ccivil_03/decreto/1851-1899/d119-a.htm>. Acesso em: 30 set. 2015.

http://www.planalto.gov.br/ccivil_03/Constituicao/Constituicao.htm>. Acesso em: 30 set. 2015.

http://www.planalto.gov.br/CCIVIL_03/leis/L9394.htm>. Acesso em: 30 set. 2015.

https://www.revistaforum.com.br/2013/04/16/reacao-de-aluno-ateu-a-bullying-acaba-compai-nosso-na-escola/. Acesso em:30/09/2015.

http://www.pragmatismopolitico.com.br/2012/11/estudantes-evangelicos-trabalho-culturaafro-brasileira.html. Acesso: 30/09/2015.

http://extra.globo.com/noticias/brasil/estudante-agredida-por-intolerancia-religiosa-dentro-deescola-nao-quer-voltar-ao-colegio-17650415.html. Acesso: 30/09/2015. 